\title{
The More Friends, the Less Political Talk? Predictors of Facebook Discussions Among College Students
}

\author{
S. Mo Jang, BA, ${ }^{1}$ Hoon Lee, $\mathrm{PhD},{ }^{2}$ and Yong Jin Park, $\mathrm{PhD}^{3}$
}

\begin{abstract}
Although previous research has indicated that Facebook users, especially young adults, can cultivate their civic values by talking about public matters with their Facebook friends, little research has examined the predictors of political discussion on Facebook. Using survey data from 442 college students in the United States, this study finds that individual characteristics and network size influence college students' expressive behavior on Facebook related to two controversial topics: gay rights issues and politics. In line with previous studies about offline political discussion, the results show that conflict avoidance and ambivalence about target issues are negatively associated with Facebook discussions. Perhaps the most interesting finding is that users who have a large number of Facebook friends are less likely to talk about politics and gay rights issues on Facebook despite having access to increasing human and information resources. Theoretical implications of these findings and future directions are addressed.
\end{abstract}

\section{Introduction}

$\mathbf{T}$ ALKING ABOUt PUbliC ISSUES with friends and family has been identified as a key factor that simulates political engagement. ${ }^{1,2}$ Interpersonal discussions of public affairs create opportunities to reflect on social problems, obtain mobilizing information, and reach informed decisions. ${ }^{3}$ Facebook, one of the world's most popular social networking sites (SNSs), has received extensive scholarly attention in this regard because a primary function of the site is to facilitate casual conversation with acquaintances at minimal cost. ${ }^{2,4}$ Scholars have paid special attention to Facebook use among young adults, who have shown a relatively low level of political engagement in the United States and other countries. ${ }^{4}$

Although these scholars have assumed that expressing views or sharing information about political or social issues on Facebook plays a critical role in developing civic values among college students, empirical efforts to explore the predictors of such activities on Facebook have been sparse. To fill this gap in the literature, this study examines both network and individual characteristics as important antecedents to political discussions on SNSs. Specifically, this investigation focuses on the extent to which the size of the audience on Facebook (i.e., Facebook friends) influences users' expressive behavior related to two controversial topics: gay rights issues and politics.

\section{Literature Review}

Facebook friends, group size, and political expression

People's perception of others influences what they talk about and how they present themselves. ${ }^{5}$ Even in social media, where conversation partners are physically invisible or sometimes unidentifiable, users create their imagined audience group and behave in such a way to meet the group's norms. ${ }^{6}$ SNS users tend to establish the boundary of a virtual audience based on the perceived reach of their posted messages, which is often regulated through privacy control functions. ${ }^{7}$ For example, the majority of Facebook users provide access to information on their accounts (e.g., Facebook Wall) only to their Facebook friends, assuming that those "friends" constitute their discussion networks. ${ }^{8}$

The influence of network size on the degree of interaction in a network has been the subject of study for a long time. ${ }^{9,10}$ Although previous research on this topic is seemingly divided, this discrepancy largely stems from the fact that network size is conceptualized in two different ways. In the literature, network size is defined either as the total number of links an individual has or as the total number of members in the network as a whole. ${ }^{11}$ When prior studies measured network size to capture an individual's capacity as a network hub, the findings indicate that greater network size stimulates more animated discussion. ${ }^{2,12}$ This makes sense because

\footnotetext{
${ }^{1}$ Department of Communication Studies, University of Michigan, Ann Arbor, Michigan.

${ }^{2}$ Nam Center for Korean Studies, School of Social Work, University of Michigan, Ann Arbor, Michigan.

${ }^{3}$ Management Communications Graduate Program in Communication, Culture and Media Studies (CCMS), School of Communications, Howard University, Washington, District of Columbia.
} 
individuals with a large network are more likely to obtain new information and encounter active discussion partners. ${ }^{12,13}$ In contrast, when network size refers to the size of a specific group, the findings suggest that a small group discussion enhances interaction and yields a productive outcome. ${ }^{4,10}$ When the size of a group remains relatively small, members are able to respond aptly to one another and competently maintain multiple dyadic interaction channels. ${ }^{14}$ In addition, this line of research indicates that members of a large group are less likely to participate in political conversations, since a large group typically consists of individuals with diverse political orientations. ${ }^{3,12}$ People are reluctant to disclose their true views about social issues when they think they are in the minority or when they are unsure whether they are in the majority. ${ }^{15}$

Applied in the context of Facebook discussion, it is critical to ask how we understand the number of Facebook friends in terms of these two definitions of network size. One might argue that the number of Facebook friends can be seen as the size of an individual user's networking ability, and that a greater number of Facebook friends facilitate discussion by supplying increased human and information resources. On the other hand, others might view that the number of Facebook friends represents the size of a user's discussion group. The assumption here is that when users update their status, they perceive that their activities on Facebook Wall are delivered to a substantial part of their friend circle. Although the boundary of this imagined audience group is not obvious, Facebook users care about the way in which their comments are "being seen" by their friends. ${ }^{16}$ According to this view, it is reasonable to expect that a greater number of Facebook friends hinder rather than facilitate Facebook discussions about public affairs. For example, users may hesitate to discuss sensitive matters on their own or friends' Walls unless they perceive that most of their imagined audience share similar views about the topics. However, as the number of Facebook friends grows exponentially, it becomes increasingly difficult to ascertain that hundreds of Facebook friends unanimously agree with a user's opinions about controversial topics. Since users' desires to be seen in a favorable light have been identified as one of the most fundamental motivations of using Facebook, ${ }^{16}$ we predict that

H1: The number of Facebook friends is negatively associated with Facebook discussions.

\section{Individual characteristics and political discussion}

Aside from the size of a discussion network, individual characteristics also foster or qualify people's willingness to express their opinions. In particular, research on political discussion has revealed that ambivalence and conflict avoidance are two important individual factors. ${ }^{3,17}$ First, ambivalence, which refers to the state in which an individual has both positive and negative attitudes toward an object, can translate into a depressed propensity to voice opinions. ${ }^{18,19}$ Empirical investigations have shown that people with strong, unwavering attitudes are inclined to state their preferences, regardless of a network environment. ${ }^{17,20,21}$ Theorists of deliberation suggest that strong attitudes serve as crucial resources, helping people overcome the risks of embarrassment, thereby encouraging them to articulate their beliefs. 22,23

The second predictor of opinion expression is conflict avoidance. In her seminal work, Mutz ${ }^{3}$ contended that some individuals confronted with a clash of perspectives hesitate to take sides largely out of their perceived obligation to avoid conflict and uphold social harmony (i.e., social accountability). From this notion, it can be inferred that those with a strong desire to avoid conflict tend to suppress their motivation to vocalize their viewpoints in order to maintain an amicable community. Furthermore, Mutz ${ }^{3}$ demonstrated that conflict-avoidant people are more likely to register a neutral or vague stance in the case of political controversy. Hence, the tendency to avoid conflict can significantly harness people's readiness to express opinions either directly or indirectly by producing greater attitudinal ambivalence. Along this line of reasoning, we expect that

H2: Ambivalence toward an issue is negatively associated with the discussion about the issue on Facebook.

H3: Conflict avoidance is negatively associated with the discussion about public affairs on Facebook.

To increase the external validity of this investigation, we set out to examine college students' Facebook discussion in two separate domains: politics and gay rights issues. Gay rights issues were chosen for this study because these issues are considered among the most popular and controversial among college students. ${ }^{24}$

\section{Method}

\section{Participants and procedure}

The sample consisted of 442 undergraduate students who were enrolled at a large Midwestern university in the United States. They participated in this study in exchange for extra course credit. This study was conducted between November 2012 and January 2013. The average age of the participants was 18.73 years $(S D=0.92)$, and $77 \%$ of them were female. The informed consent and following measures were completed through an online survey.

\section{Measures}

Facebook use. Respondents were first asked if they had Facebook accounts. Two students who answered in the negative were excluded from further analysis. Facebook use was assessed using an item from previous research. ${ }^{25}$ Respondents were asked to report how many minutes they spent using Facebook each day in the preceding week. The response categories consisted of $1=$ "never," 2 = "less than 10 minutes," $3=$ " 11 to 30 minutes," $4=31$ to 60 minutes," $5=1$ to 2 hours," and $6=$ "more than 2 hours"; $M=4.51, S D=1.12$. As we wanted to examine the potential influence of specific network characteristics (i.e., Facebook friends), we adopted this minute-based measure of Facebook use as a control. Thus, we controlled for the fact that frequent users might have more opportunities to engage in public discussion on the site.

Facebook friends. We used an open-ended question to ask how many total Facebook Friends they had. The average number of Facebook friends was $893.73(S D=488.86)$.

Talking about gay rights issues on Facebook. Respondents rated how much they agreed or disagreed with two statements: (a) 'I've expressed my thoughts about 
gay-related issues on Facebook by updating status or writing comments," and (b) "I've shared the links that contain information about gay-related issues on Facebook." The two responses varied from $1=$ "strongly disagree" to 7 " strongly agree" and were averaged $(M=2.54, S D=1.83, r=0.92)$.

Talking about politics on Facebook. Respondents indicated how much they agreed or disagreed with two statements: (a) "I've expressed my thoughts about politics on Facebook by updating status or writing comments," and (b) "I've shared the links that contain information about politics on Facebook." The two responses ranged from 1= "strongly disagree" to $7=$ "strongly agree" and were averaged $(M=2.54, S D=1.83, r=0.89)$.

Ambivalence toward gays. To assess ambivalence, which is defined as concurrent operation of contrasting views, we measured both positive and negative attitudes toward gays. Respondents were provided with four statements adapted from pro- and antigay scales ${ }^{26}$ and asked to indicate their gay attitudes on a 7-point scale, ranging from $1=$ "strongly disagree" to $7=$ "strongly agree." The first two items from progay scales included (a) "I wish I had more gay friends," and (b) "Gay civil rights are critical political issues." The next two items from antigay scales were (a) "I do not understand how two men can be in love with each other," and (b) "Homosexual love is just not as sacred as the love between a man and a woman." These were combined to form a measure of ambivalence using the formula described in Thompson et al. ${ }^{19}$ The formula captures average intensity and level of similarity between pro- and antigay measures $(M=-0.02, S D=1.74)$.

Ambivalence $=($ positive + negative $) / 2-\mid$ positive - negative $\mid$

Ambivalence toward politics. To assess ambivalence with regard to political views, we asked respondents to indicate their feelings toward two major political parties in a "feeling thermometer" ranging from 0 to 100 . The same formula was applied to calculate ambivalence toward politics $(M=4.91, S D=32.68)$.

Conflict avoidance. Respondents were provided with two statements and asked to express the extent to which they agreed with each statement on a 7-point scale, ranging from $1=$ "strongly disagree" to $7=$ "strongly agree." The two statements included (a) "When I talk about public issues, sometimes it is best not to say what I really think," and (b) "I am reluctant to talk about public issues when I am with people of different perspectives." The two items were averaged $(M=3.06, S D=1.64, r=0.65)$.

Control variables. Political ideology was assessed with a single 7-point scale item, ranging from $1=$ "very conservative" to $7=$ "very liberal" $(M=4.56, S D=1.41)$. Religiosity was measured based on the mean response to two 5-point scale items $(M=3.31, S D=1.41, r=0.49)$. Participants were asked (a) "How often do you go to church?" (1 = "never," $5=$ "more than once a week"), and (b) "How important is religion to your life?" (1= "not at all important," $5=$ "extremely important"').

\section{Results}

To examine the predictors of college students' political discussion on Facebook, hierarchical multiple regressions were conducted. We first regressed the discussion of gay rights issues, and the results are summarized in Table 1. The first block of predictors, consisting of control variables including gender, religiosity, and political ideology, significantly predicted the discussion of gay rights issues. Respondents with greater religiosity and conservative ideology appeared to be less likely to talk about talk about gay rights issues on Facebook. To test H1, $\mathrm{H} 2$, and H3, the full model includes the number of Facebook friends, ambivalence toward gays, and conflict avoidance as the second block of predictors. All hypotheses were supported in the context of gay rights issues. Whereas time spent on Facebook did not reach statistical significance, the number of Facebook friends was inversely associated with Facebook discussion about gay rights issues. In addition, in line with previous research, ${ }^{3,17}$ individual characteristics including ambivalence and conflict avoidance were negatively associated with the outcome variable.

To assess whether these findings are applicable to other controversial domains aside from gay rights issues, we ran another multiple regression that predicted political discussion on Facebook. As Table 2 shows, the findings confirmed that the number of Facebook friends and ambivalence are negatively associated with Facebook discussion about controversial issues ( $\mathrm{H} 1$ and $\mathrm{H} 2$ ). However, unlike the previous results, conflict avoidance, religiosity, and political ideology did not appear to be significant predictors. Instead, gender was significantly associated with the dependent variable, suggesting that female students are less likely to talk about politics on Facebook.

Table 1. Multiple Regression Predicting Talking About Gay Issues on Facebook $(N=440)$

\begin{tabular}{|c|c|c|c|c|c|c|}
\hline & \multicolumn{3}{|c|}{ Block 1} & \multicolumn{3}{|c|}{ Block 2} \\
\hline & $B$ & $S E B$ & $\beta$ & $B$ & $S E B$ & $\beta$ \\
\hline Gender (female) & 0.26 & 0.19 & 0.06 & 0.04 & 0.20 & 0.01 \\
\hline Religiosity & -0.18 & 0.06 & $-0.14 * *$ & -0.13 & 0.06 & $-0.10^{*}$ \\
\hline Political ideology (liberal) & 0.20 & 0.05 & $0.19 * * *$ & 0.12 & 0.05 & $0.11 *$ \\
\hline Facebook use & & & & 0.08 & 0.08 & 0.05 \\
\hline Facebook friends & & & & 0.00 & 0.00 & $-0.11 *$ \\
\hline Conflict avoidance & & & & -0.14 & 0.06 & $-0.13^{*}$ \\
\hline Ambivalence toward gays & & & & -0.16 & 0.06 & $-0.16 * *$ \\
\hline$R^{2}$ changes & \multicolumn{3}{|l|}{$0.07 * * *$} & \multicolumn{3}{|c|}{$0.06^{* * *}\left(\right.$ Final $\left.R^{2}=0.13\right)$} \\
\hline
\end{tabular}

Note: $* \mathrm{p}<0.05, * * \mathrm{p}<0.01, * * * \mathrm{p}<0.001$ 
Table 2. Multiple Regression Predicting Talking About Politics on Facebook $(N=440)$

\begin{tabular}{|c|c|c|c|c|c|c|}
\hline & \multicolumn{3}{|c|}{ Block 1} & \multicolumn{3}{|c|}{ Block 2} \\
\hline & $B$ & $S E B$ & $\beta$ & $B$ & $S E B$ & $\beta$ \\
\hline Gender (female) & -0.34 & 0.20 & $-0.08 *$ & -0.44 & 0.20 & $-0.11 *$ \\
\hline Religiosity & -0.05 & 0.06 & -0.04 & -0.04 & 0.06 & -0.03 \\
\hline Political ideology (liberal) & 0.16 & 0.05 & $0.15^{* *}$ & 0.11 & 0.06 & 0.10 \\
\hline Facebook use & & & & 0.13 & 0.08 & 0.08 \\
\hline Facebook friends & & & & 0.00 & 0.00 & $-0.12 *$ \\
\hline Conflict avoidance & & & & -0.06 & 0.06 & -0.05 \\
\hline Ambivalence toward gays & \multirow{2}{*}{\multicolumn{3}{|c|}{$0.03 * *$}} & -0.01 & 0.00 & $-0.13 * *$ \\
\hline$R^{2}$ changes & & & & \multicolumn{3}{|c|}{$0.04 * *\left(\right.$ Final $\left.R^{2}=0.07\right)$} \\
\hline
\end{tabular}

Note: $* \mathrm{p}<0.05, * * \mathrm{p}<0.01, * * * \mathrm{p}<0.001$.

\section{Discussion}

Political communication scholars have welcomed SNSs as a potential platform for political discussion and found positive links between SNS use and civic values. ${ }^{1,2,27}$ Yet, little research has examined who actually exchanges opinions about public affairs through SNSs and who benefits from such activities. This study offers empirical evidence that college students' political conversation on Facebook is highly contingent on both network size and individual differences.

First, the results show that users with more Facebook friends are less likely to talk about gay rights issues or politics on the site. This clearly opposes the view suggesting that more friends would provide more frequent opportunities to talk about public issues. Instead, our findings support the contention that a small group is more effective for deliberation than a large group. ${ }^{1,10}$ Numerous studies have shown that small group discussion yields more productive outcomes, especially when it is important to consider a wide range of opinions among group members. ${ }^{10}$ Similarly, a recent study about Facebook found that if users interacted with more than 500 actual friends through Facebook, the users' social capital gains decreased. ${ }^{4}$

In addition, the current findings are consistent with the idea that a large group tends to preclude open discussion because its members are presumed to have more difficulties reducing the uncertainty of other group members. ${ }^{28,29}$ When users realize hundreds of Facebook friends are listening to them and that it is hard to estimate the extent to which other group members agree with them, they may hesitate to express their honest views on sensitive issues. As Facebook friends now come from diverse parts of users' lives, including school, family, relatives, church, and various community groups, ${ }^{6}$ users are susceptible to cross pressures from multiple group norms co-residing within the same network. ${ }^{30}$

Another interesting finding is that respondents who are more religious and conservative tend to be quiet about gay rights issues on Facebook. This can be explained by the spiral of silence theory, which hypothesizes that when people perceive themselves to be in the minority, they do not publicly express controversial opinions. ${ }^{15}$ It is possible religious and conservative students do not feel comfortable sharing their candid opinions about gay rights issues when perceiving that the dominant opinion climate among college students supports gay rights issues. To examine this possibility further, future work needs to measure users' perceptions of the opinion climate among their Facebook friends.
Several limitations to this study should be noted. First, this study focused primarily on expressive activities visible on users' personal Facebook Wall and did not take into account more private communication channels available on Facebook, such as messages and group activities. It is possible that users feel more comfortable disclosing their attitudes about controversial issues when they have increased control over their audience. ${ }^{31}$ To explore this possibility, future research should assess various Facebook activities individually. Second, the student respondents were not drawn from random sampling. Replications with more representative samples would strengthen confidence in our findings. Finally, as the survey data are cross-sectional, the observed relationships must be interpreted as correlational. We are unable to ascertain whether a large number of Facebook friends decreases expressive behavior or whether the causal influence works in the opposite direction, but this should be an important inquiry in the future.

\section{Author Disclosure Statement}

No competing financial interests exist.

\section{References}

1. Huckfeldt R, Johnson PE, Sprague J. (2004) Political disagreement: the survival of diverse opinions within communication networks. Cambridge: Cambridge University Press.

2. Valenzuela SN, Kim Y, Gil de Zuniga H. Social networks that matter: exploring the role of political discussion for online political participation. International Journal of Public Opinion Research 2012; 24:163-184.

3. Mutz DC. (2006) Hearing the other side: deliberative versus participatory democracy. Cambridge: Cambridge University Press.

4. Ellison NB, Steinfield C, Lampe C. Connection strategies: social capital implications of Facebook-enabled communication practices. New Media \& Society 2011; 13:873-892.

5. Goffman E. (1959) The presentation of self in everyday life. Garden City, NY: Doubleday Anchor.

6. Bernstein MS, Bakshy E, Burke M, et al. (2003) Quantifying the invisible audience in social networks. Proceedings of the SIGCHI Conference on Human Factors in Computing Systems. New York: ACM Press, pp. 21-30.

7. Park YJ. Digital literacy and privacy behavior online. Communication Research 2013; 40:215-236.

8. Stutzman F, Kramer-Duffield J. (2010) Friends only: examining a privacy-enhancing behavior in Facebook. 
Proceedings of the SIGCHI Conference on Human Factors in Computing Systems: New York: ACM Press, pp. 15531562.

9. Campbell SW, Kwak N. Political involvement in "mobilized" society: the interactive relationships among mobile communication, network characteristics, and political participation. Journal of Communication 2011; 61:1005-1024.

10. Fay N, Garrod S, Carletta J. Group discussion as interactive dialogue or as serial monologue: the influence of group size. Psychological Science 2000; 11:481-486.

11. Parks MR. (2011) Social networks and the life of relationships. In Knapp ML, Daly JA, eds. The Sage handbook of interpersonal communication. Thousand Oaks, CA: Sage. pp. 355-388.

12. Eveland WP, Hively MH. Political discussion frequency, network size, and "heterogeneity" of discussion as predictors of political knowledge and participation. Journal of Communication 2009; 59:205-224.

13. McLeod JM, Scheufele DA, Moy P. Community, communication, and participation: the role of mass media and interpersonal discussion in local political participation. Political Communication 1999; 16:315-336.

14. Steiner, ID. (1972) Group process and productivity. New York: Academic Press.

15. Noelle-Neumann E. (1993) The spiral of silence: public opinion-our social skin. Chicago: The University of Chicago Press.

16. Tufekci Z. Can you see me now? Audience and disclosure regulation in online social network sites. Bulletin of Science, Technology \& Society 2008; 28:20-36.

17. Glynn CJ, McLeod JM. Public opinion du jour: an examination of the spiral of silence. Public Opinion Quarterly 1984; 48:731-740.

18. Armitage CJ, Conner M. Attitudinal ambivalence: a test of three key hypotheses. Personality \& Social Psychology Bulletin 2000; 26:1421-1432.

19. Thompson MM, Zanna MP, Griffin DW. (1995) Let's not be indifferent about (attitudinal) ambivalence. In Petty RE, Krosnick JA, eds. Attitude strength: antecedents and consequences. Hillsdale, NJ: Lawrence Erlbaum. pp. 361-386.

20. Lasorsa DL. Effects of newspaper competition on public opinion diversity. Journalism \& Mass Communication Quarterly 1991; 68:38-47.

21. Matthes J, Morrison KR, Schemer C. A spiral of silence for some: attitude certainty and the expression of political minority opinions. Communication Research 2010; 37:774-800.
22. Mansbridge JJ. (1983) Beyond adversary democracy. Chicago: The University of Chicago Press.

23. Schudson M. Embarrassment and Erving Goffman's idea of human nature. Theory \& Society 1984; 13:633-648.

24. Pew Research Center. (2013) Growing support for gay marriage: Changed minds and changing demographics. Retrieved from www.people-press.org/2013/03/20growingsupport-for-gay-marriage-changed-minds-and-changingdemographics/ (accessed May, 11, 2013).

25. Ellison NB, Steinfield C, Lampe C. The benefits of Facebook "friends:" social capital and college students' use of online social network sites. Journal of Computer Mediated Communication 2007; 12:1143-1168.

26. Callahan MP, Vescio TK. Core American values and the structure of antigay prejudice. Journal of Homosexuality 2011; 58:248-262.

27. Chan M, Guo J. The role of political efficacy on the relationship between Facebook use and participatory behaviors: a comparative study of young American and Chinese adults. CyberPsychology, Behavior, \& Social Networking 2013; 16:460-463.

28. Berger CR, Calabrese RJ. Some explorations in initial interaction and beyond: toward a developmental theory of interpersonal communication. Human Communication Research 1975; 1:99-112.

29. Ramirez A, Walther JB, Burgoon JK, et al. Information seeking strategies, uncertainty, and computer mediated communication. Human Communication Research 2002; 28:213-228.

30. Lazarsfeld PF, Berelson B, Gaudet H. (1944) The people's choice: how the voter makes up his mind in a presidential campaign. New York: Columbia University Press.

31. Jang SM, Challenges to selective exposure: examining selective seeking and avoidance in a multitasking media environment. Mass Communication \& Society 2014; (In press).

Address correspondence to: S. Mo Jang Department of Communication Studies University of Michigan 105 S. State St. NorthQuad, RM 5348 Ann Arbor, MI 48109

E-mail:mo7788@gmail.com 


\section{This article has been cited by:}

1. Ioana A. Cionea, Cameron W. Piercy, Christopher J. Carpenter. 2017. A profile of arguing behaviors on Facebook. Computers in Human Behavior 76, 438-449. [Crossref]

2. S Mo Jang, Yong Jin Park, Hoon Lee. 2017. Round-trip agenda setting: Tracking the intermedia process over time in the ice bucket challenge. Journalism: Theory, Practice \& Criticism 18:10, 1292-1308. [Crossref]

3. Qihao Ji. 2017. Social Media News Use and Political Discussion. Electronic News 11:1, 3-19. [Crossref]

4. Kim Mihee. 2016. Facebook's Spiral of Silence and Participation: The Role of Political Expression on Facebook and Partisan Strength in Political Participation. Cyberpsychology, Bebavior, and Social Networking 19:12, 696-702. [Abstract] [Full Text HTML] [Full Text PDF] [Full Text PDF with Links]

5. Stephan Winter, German Neubaum. 2016. Examining Characteristics of Opinion Leaders in Social Media: A Motivational Approach. Social Media + Society 2:3, 205630511666585. [Crossref]

6. Leticia Bode. 2016. Pruning the news feed: Unfriending and unfollowing political content on social media. Research \& Politics 3:3, 205316801666187. [Crossref]

7. Emily K. Vraga, Leticia Bode, Anne-Bennett Smithson, Sonya Troller-Renfree. 2016. Blurred lines: Defining social, news, and political posts on Facebook. Journal of Information Technology \& Politics 13:3, 272-294. [Crossref]

8. E. Stoycheff. 2016. Under Surveillance: Examining Facebooks Spiral of Silence Effects in the Wake of NSA Internet Monitoring. Journalism \& Mass Communication Quarterly 93:2, 296-311. [Crossref]

9. Marder Ben, Houghton David, Joinson Adam, Shankar Avi, Bull Eleanor. 2016. Understanding the Psychological Process of Avoidance-Based Self-Regulation on Facebook. Cyberpsychology, Behavior, and Social Networking 19:5, 321-327. [Abstract] [Full Text HTML] [Full Text PDF] [Full Text PDF with Links]

10. Yun-Cheol Heo, Ji-Young Park, Ji-Young Kim, Han-Woo Park. 2016. The emerging viewertariat in South Korea: The Seoul mayoral TV debate on Twitter, Facebook, and blogs. Telematics and Informatics 33:2, 570-583. [Crossref]

11. Rebecca Ping Yu. 2016. The relationship between passive and active non-political social media use and political expression on Facebook and Twitter. Computers in Human Bebavior 58, 413-420. [Crossref]

12. Emily Vraga, Leticia Bode, Sonya Troller-Renfree. 2016. Beyond Self-Reports: Using Eye Tracking to Measure Topic and Style Differences in Attention to Social Media Content. Communication Methods and Measures 10:2-3, 149-164. [Crossref]

13. Yifat Mor, Neta Kligler-Vilenchik, Ifat Maoz. 2015. Political Expression on Facebook in a Context of Conflict: Dilemmas and Coping Strategies of Jewish-Israeli Youth. Social Media + Society 1:2, 205630511560675. [Crossref]

14. S. Mo Jang, Josh Pasek. 2015. Assessing the Carrying Capacity of Twitter and Online News. Mass Communication and Society 18:5, 577-598. [Crossref]

15. S. Mo Jang. 2014. Challenges to Selective Exposure: Selective Seeking and Avoidance in a Multitasking Media Environment. Mass Communication and Society 17:5, 665-688. [Crossref] 